\title{
Atividades investigativas e o desenvolvimento de habilidades e competências: um relato de experiência no curso de Física da Universidade Federal do Pará
}

Investigative activities and the development of skills and competences: an experience report of the Physics course of the Federal University of Pará

\author{
Simone Fraiha ${ }^{1}$, Waldomiro Paschoal Jr${ }^{1}$, Silvana Perez ${ }^{* 1}$, Clara E. S. Tabosa ${ }^{1}$, João Paulo da \\ Silva Alves ${ }^{2}$, Charles Rocha Silva ${ }^{2}$ \\ ${ }^{1}$ Universidade Federal do Pará, Faculdade de Física, Belém, PA, Brasil \\ ${ }^{2}$ Instituto Federal do Pará, Departamento de Física, Belém, PA, Brasil
}

Recebido em 19 de Fevereiro, 2018. Revisado em 08 de Maio, 2018. Aceito em 18 de Maio, 2018.

\begin{abstract}
Neste trabalho apresentamos um relato de experiência de uma disciplina piloto implementada em uma turma de ingressantes no curso de graduação em Física (licenciatura e bacharelado) da Universidade Federal do Pará, durante o primeiro semestre de 2017. Tendo como base o uso de atividades investigativas no ensino, durante o semestre de trabalho, os estudantes foram divididos em equipes e a cada uma delas foi proposto um problema de Ciências em aberto, para o qual os alunos tiveram que emitir hipóteses, planejar um aparato experimental, coletar dados e interpretar os resultados de forma a responder o problema proposto. Na análise da proposta didática, apresentamos os principais aspectos pontuados pelos professores que aplicaram a metodologia. Em se tratando diretamente dos estudantes, pôde-se perceber um maior engajamento nas atividades propostas pelo professor e um aumento da autoeficácia. Indiretamente, observou-se um maior respeito à liberdade criativa e ao ritmo de aprendizado de cada aluno no que tange ao aprendizado dos conceitos de Física relevantes, bem como ao desenvolvimento de competências relacionadas à capacidade de resolver problemas de pesquisa e do seu cotidiano. Entre outros aspectos pontuados pelos professores destacam-se uma sensibilidade da metodologia à turma, bem como à escolha dos problemas propostos.
\end{abstract}

Palavras-chave: atividades investigativas, ensino de Física, formação de professores, natureza da ciência

In this work we present an experience report of a pilot discipline implemented in a group of students enrolled in the undergraduate course in Physics (licentiate and bachelor's degree) at the Federal University of Pará, during the first semester of 2017. Based on the use of investigative activities, during the semester, the students were divided into teams and for each them it was proposed an open-ended science problem, for which students had to make hypotheses, plan an experimental apparatus, collect data and interpret the results with the goal of responding the proposed problem. In the analysis of the didactic proposal, we present the main aspects punctuated by the teachers who applied the methodology. When dealing directly with the students, there was a greater involvement in the activities proposed by the teacher and an increase in self-efficacy. Indirectly, there was a greater respect for the creative freedom and learning pace of each student in learning the relevant physics concepts, as well as the development of competences related to the ability to solve research problems and in their daily life. Among other points scored by teachers, a sensitivity of the methodology to the class is highlighted, as well as to the choice of proposed problems.

Keywords: investigative activities, Physics Teaching, Teacher Training, Nature of Science

\section{Introdução}

Um dos grandes desafios educacionais da sociedade contemporânea do século XXI é pensar uma educação que contribua para formar cidadãos capazes de opinar e tomar decisões sobre temas que envolvam ciência e tecnologia e sobre como a sociedade recebe, pensa e trabalha tais temas, embasados em uma argumentação científica, fundamentada no conhecimento adquirido pela comunidade

*Endereço de correspondência: silperez_1972@hotmail.com de pesquisadores de todas as áreas ao longo da história da humanidade. O cidadão do novo milênio deve se apropriar criticamente do conhecimento disponível, e usá-lo para viver melhor em sociedade, propondo e efetuando transformações que contribuam para essa melhora 1].

Entretanto, quando se trata da sociedade se posicionar em questões de cunho científico, que sejam abrangentes e que perpassem por esferas como a ética, política etc., vê-se exemplos de decisões problemáticas ainda por toda parte 2. Um atual exemplo que ilustra esse comportamento é 
o posicionamento do então presidente dos Estados Unidos da América, Donald Trump, que nega a existência do aquecimento global bem como de suas consequências, contrariando assim um relatório feito por treze agências ligadas ao próprio governo, que apresentam previsões calamitosas sobre as mudanças climáticas relacionadas com o fenômeno 3].

No cenário brasileiro os desafios de pensar tal educação são maiores ainda. É urgente a necessidade de desenvolver estratégias que possam alavancar os níveis de educação em seu contexto mais geral, perpassando pela educação formal e pela educação para a cidadania. Os dados apresentados pelo Ministério da Educação [4] mostram que aproximadamente metade dos estudantes que chegam ao quinto ano do ensino fundamental em todo o Brasil apresentam falhas consideráveis em seu processo de letramento [5] e numeramento [6]. Além disso, ainda mais grave é a situação da alfabetização científica no país. Entendida como a tarefa educacional de oferecer condições para que os alunos sejam capazes de "tomar decisões conscientes sobre problemas de sua vida e da sociedade relacionados a conhecimentos científicos " [7], a iniciação à alfabetização científica nos anos iniciais do ensino fundamental fica a critério de cada escola, onde muitas vezes é abandonada.

Estes estudantes, com suas falhas de formação, continuam seus estudos e chegam ao ensino médio, em geral, sem o domínio mínimo da língua portuguesa e da matemática 8] e ainda sem estarem inseridos criticamente no ensino de ciências. É nesse momento que se deparam com o ensino de Física, Química, entre outros, que exigem deles interpretações mais aprimoradas de textos e dados quantitativos.

Sendo assim, não faz mais sentido pensar em reformas educacionais que se concentrem unicamente na discussão de conteúdos específicos, em particular na área de Ciências Naturais, objeto desse trabalho. É necessária uma ampla reflexão sobre novas metodologias de ensino, que promovam uma aprendizagem eficiente nos estudantes bem como o desenvolvimento de habilidades e competências que possibilitem a formação de cidadãos conscientes e preparados para os novos desafios que se colocam na sociedade atual. Vários documentos oficiais caminham nessa direção, como por exemplo, o Plano Nacional de Educação 2014-2024 [9], que destaca:

\footnotetext{
"a elaboração de um plano de educação não pode prescindir de incorporar os princípios do respeito aos direitos humanos, à sustentabilidade socioambiental, à valorização da diversidade e da inclusão e à valorização dos profissionais que atuam na educação de milhares de pessoas todos os dias"
}

Muito embora entenda-se a importância desses direcionamentos oficiais, no geral eles sozinhos não chegam até a sala de aula, não sendo observadas mudanças significativas nos índices educacionais brasileiros. Parte desse problema está ligado à formação dos futuros professores, dentro das universidades. Os currículos dos cursos de licenciatura em geral são engessados em estruturas disciplinares, com pouca ou nenhuma presença de multi, inter ou transdisciplinaridade, e com pouca discussão e reflexão sobre a necessidade e o uso de abordagens metodológicas alternativas. Muitas vezes são extremamente "bacharelizados" [10], tanto nas áreas de Ciências da Natureza, quanto em Humanas e Biológicas. Segundo pesquisa desenvolvida por Gatti e Nunes [11] em cursos de licenciatura em Letras e em Ciências Biológicas, conhecimentos específicos de área representam mais da metade das disciplinas presentes nas grades curriculares dos cursos analisados, há pouca articulação entre as disciplinas de formação específica de área e as de formação pedagógica, assim como pouca discussão de saberes associados a tecnologias. O professor formado nesses cursos não se sente seguro para trabalhar com novas metodologias e acaba repetindo em sua sala de aula a abordagem didática tradicional com a qual conviveu praticamente em toda a sua formação [12], dando continuidade assim, a um processo cíclico de ensino-aprendizagem onde o estudante é passivo e se torna apenas um receptáculo de informações muitas vezes desconexas de sua realidade. Para Manrique 13, a desarticulação entre os conhecimentos específicos e os pedagógicos, somada à descontextualização dentro dos cursos de licenciatura, tem impacto direto nas futuras atividades docentes.

Neste trabalho partimos do pressuposto de que uma mudança metodológica no ensino de ciências na educação básica é potencializada se na sua formação inicial dentro da universidade, os discentes e futuros professores dessas disciplinas estudam os conteúdos específicos com abordagens metodológicas diferenciadas, e que, mais especificamente, o uso de Atividades Investigativas no Ensino de Física potencializa o desenvolvimento das habilidades e competências necessárias para a investigação científica [14]. Assim, apresentamos aqui um projeto piloto desenvolvido com estudantes de primeiro semestre do curso de graduação em Física da Universidade Federal do Pará (UFPA) durante o ano de 2017, que utilizou problemas em aberto para revisar os conteúdos de Física da educação básica. Essa proposta metodológica já havia sido implementada no curso, como atividade complementar em uma disciplina de final de graduação e apresentou resultados promissores. Em [15] Perez e colaboradores descrevem um dos experimentos desenvolvidos na época por uma das equipes e sua fundamentação nas leis da Física.

Na Sec. II, apresentamos uma revisão de aspectos conceituais sobre o ensino de Ciências e o desenvolvimento de habilidades e competências para a investigação científica que promovem o alcance de objetivos educacionais requeridos nas Matrizes Curriculares oficiais para a educação e para a cidadania. A seguir, o plano de curso é apresentado na Sec. III, para finalmente na Sec. IV discutirmos os principais aspectos observados. As considerações finais são descritas na Sec.V. 


\section{Sobre o desenvolvimento de habilidades e competências no ensino de Física}

Nas últimas décadas, o foco das pesquisas em Ensino de Ciências migrou dos produtos da ciência (ensino de conteúdos específicos) para os processos da ciência (competências e habilidades). Convém-se que esse movimento se iniciou nos EUA com a publicação do documento intitulado Science for All Americans, que entre outras coisas, estabeleceu que até 2061, ano de aparição do Cometa Haley, todos os cidadãos americanos deveriam estar alfabetizados cientificamente 16 . Neste documento foram apresentadas doze competências, sendo a primeira delas associada com o termo Natureza da Ciência (NdC), que trata da natureza do pensamento científico e os métodos da investigação da Ciência [17.

Atrelado à competência associada à $\mathrm{NdC}$, podemos considerar duas linhas de seguimento no âmbito das habilidades. Segundo Braga [16], a primeira delas trata da argumentação, que implica na tomada de decisões sobre questões polêmicas, como a destacada na introdução, habilidade esta que pode ser desenvolvida por meio de discussões e debates sobre a construção do conhecimento científico, e isso pode ser feito por exemplo, por meio do estudo do desenvolvimento histórico dos conceitos científicos.

Já a segunda linha parte do pressuposto de que só se aprende sobre ciência fazendo ciência. Esse tipo de pensamento vai ao encontro de abordagens didáticas que promovem atividades intelectuais por parte dos alunos ao invés do ensino tradicional meramente expositivo. Um exemplo nessa direção são as atividades investigativas no ensino. Zômpero e Laburú [18 pontuam que embora existam diferentes abordagens para o desenvolvimento de atividades investigativas no ensino, todas "essas atividades devem sempre partir de um problema para ser analisado, para o qual os alunos devem emitir hipóteses, realizar um planejamento de atividades, interpretar as informações e comunicar os resultados".

Assim, segundo Villagrá e colaboradores 19], por meio das atividades investigativas o aluno constrói significativamente seu conhecimento do mundo natural, e tão importante quanto, passa a compreender o processo de fazer ciência. Pasqualetto e colaboradores [20] apresentam uma revisão da literatura sobre aprendizagem baseada em projetos no ensino de Física.

Vale salientar que a simples escolha de um problema a ser desenvolvido em sala de aula não garante o efetivo uso de atividades investigativas. Muitas vezes, a falta de domínio do conteúdo específico, conflitos com a coordenação pedagógica da escola, falta de aparato experimental entre outros motivos, fazem com que o professor não desenvolva em sua plenitude o problema em estudo, comprometendo o uso da metodologia. Nesse sentido, Schwarz e Gwekwerere 21] apud Villagrá e colabora- dores [22] estabelecem seis tipos de unidades didáticas investigativas:

1. prática incoerente - embora haja um problema a ser estudado, os conceitos abordados possuem pouca ou nenhuma relação com ele;

2. prática coerente - o problema inicial é muito centrado no aparato experimental, e ao aluno é exigida pouca reflexão teórica;

3. acadêmica - os conceitos específicos são abordados de forma tradicional, e embora haja atividade experimental, ela é totalmente dirigida pelo professor;

4. projeto - embora existam atividades experimentais, elas são muito direcionadas pelo professor;

5. indagativa - é muito parecida com uma atividade investigadora (abaixo descrita), porém com um pouco mais de controle por parte do professor. Nela são realizados experimentos sequenciados e perguntas guiadas pelo professor, de forma a que o aluno construa por si só o conhecimento.

6. investigadora - o aluno tem total liberdade para que, partindo de um problema inicial de seu interesse, desenvolva hipóteses e experimentos e gere dados para chegar a uma conclusão.

Neste trabalho apresentamos um relato de experiência de uma proposta de disciplina que buscou utilizar atividades investigativas para revisar os conteúdos de Física estudados na educação básica. O público alvo foram estudantes de primeiro semestre do curso de graduação em Física da UFPA. Na classificação acima, entendemos que a proposta tem aspectos tanto de atividades indagativas quanto de investigadoras, se aproximando mais da última. Conforme veremos na próxima seção, embora tenha ocorrido algum direcionamento das atividades, não houve perguntas guiadas pelo professor nem experimentos sequenciados para toda a turma. Por outro lado, não houve uma garantia de que os temas de cada umas das equipes eram de interesse dos estudantes, pois estes foram sorteados. Na próxima seção detalhamos o desenvolvimento da disciplina.

\section{A proposta desenvolvida}

A proposta didática adotada foi baseada no ensino por investigação, onde o estudante desenvolve em equipe um problema em aberto. Os temas foram preestabelecidos pelo professor da disciplina no início do semestre e escolhidos do International Young Physicist Tournment (IYPT) 23.

O IYPT é um torneio internacional de Física, voltado para estudantes do ensino médio, que ocorre anualmente. As últimas edições aconteceram em Singapura, Rússia, Tailândia, Reino Unido e Taiwan. A cada ano é proposta uma lista de problemas de natureza investigativa, que estimulam o estudante a desenvolver a argumentação científica e entender a natureza da ciência. Uma lista de 
referências básicas também é apresentada e serve de guia de pesquisa para as equipes.

A disciplina na qual ocorreu a experiência aqui relatada é de primeiro semestre do curso de graduação em Física e tem como objetivo discutir conceitualmente e de maneira contextualizada temas de Física do cotidiano do estudante e sua formalização científica. Como referência são adotados os livros "Física Conceitual" [24], "O universo dos quanta. Uma breve história da Física Moderna" 25] e "O circo voador da Física" 26.

O relato aqui apresentado refere-se ao primeiro semestre de 2017, sendo este o primeiro de aplicação da metodologia na disciplina, e é relativo a uma turma com 50 alunos. A classe foi dividida livremente em dez equipes, sendo cada uma delas identificada por um nome de escolha dos próprios estudantes.

Os temas desenvolvidos foram (apenas um dos problemas não foi escolhido dos propostos pelo IYPT, tendo sido obtido de um trabalho de conclusão de curso de licenciatura em Física da UFPA [27]):

1. Canhão Eletromagnético (IYPT 2010) - Um solenóide pode ser usado para atirar uma pequena bola. Construa um dispositivo no qual um capacitor carregado a no máximo $50 \mathrm{~V}$ é usado para energizar a bobina do solenóide. Investigue os parâmetros e maximize a velocidade da bola;

2. Pêndulo Magnético (IYPT 2015) -Faça um pêndulo leve com um pequeno ímã em sua extremidade. Um eletroímã adjacente conectado a uma fonte de corrente alternada de frequência muito superior à frequência natural do pêndulo pode levar a oscilações não-amortecidas com várias amplitudes. Estude e explique o fenômeno;

3. Geladeira de Potes (IYPT 2014) - A "geladeira de potes" (do inglês pot-in-pot refrigerator) é um dispositivo que mantém alimentos resfriados utilizando o princípio do resfriamento evaporativo. Ela consiste de um vaso colocado dentro de um vaso maior, com o espaço entre eles preenchido por um material seco e poroso, como areia. Como é possível obter o melhor efeito de resfriamento?

4. Coeficiente de difusão (IYPT 2014) - Usando um microscópio, observe o movimento browniano de uma partícula com tamanho da ordem de um micrômetro. Investigue como o coeficiente de difusão depende do tamanho e do formato da partícula;

5. Invente você mesmo (IYPT 2017) - Construa um dispositivo passivo capaz de proporcionar uma aterrisagem segura para um ovo de galinha (que não tenha sido cozido) quando derrubado de uma altura de 2,5 m em uma superfície dura. O dispo-sitivo deve cair junto com o ovo. Qual é o menor tamanho do dispositivo que você pode utilizar?

6. A dança dos surdos (UFPA 2017) - Muito embora não possam ouvir, os surdos são capazes de dançar ao ritmo de músicas. Como esse fenômeno ocorre? Investigue os parâmetros físicos relevantes;
7. Músculo Artificial (IYPT 2015) - Amarre uma linha de pesca polimerizada a uma furadeira e aplique tensão à linha. À medida que ela é enrolada, a fibra formará pequenas bobinas num arranjo semelhante ao de uma mola. Aplique calor às bobinas para que se fixem permanentemente nesta forma. Quando você aplicar calor novamente, a bobina vai se contrair. Investigue este músculo artificial;

8. Usina de Velas (IYPT 2014) - Projete um dispositivo que converta o calor da chama de uma vela em energia elétrica. Investigue como diferentes aspectos desse dispositivo afetam sua eficiência;

9. Pêndulo Defasado (IYPT 2016) - Um pêndulo consiste de uma linha resistente e um peso. Quando a base do pêndulo começa a se mover ao longo de uma circunferência horizontal, o peso começa a traçar uma circunferência que pode ter um raio menor, sob certas circunstâncias. Investigue o movimento e as trajetórias estáveis do peso;

10. Ouvindo a Luz (IYPT 2013) - Cubra metade do interior de um frasco com uma camada de fuligem e faça um furo em sua tampa. Quando a luz de uma lâmpada conectada a uma fonte de corrente alternada atinge a parede escura do frasco, um som pode ser ouvido. Explique o fenômeno.

No início do semestre houve a apresentação da proposta em um palestra na semana dos calouros, onde se discutiu a metodologia do ensino por investigação. Com essa apresentação prévia, pôde-se observar uma aceitação da metodologia por boa parte dos estudantes envolvidos, antes mesmo do início das aulas.

Na primeira aula do curso, os temas foram apresentados e ocorreu o sorteio. As atividades ao longo do semestre foram divididas em três momentos, detalhados a seguir.

\subsection{Fase 1 - Estudo inicial do problema}

Esta fase durou aproximadamente um mês e meio. Nas duas primeiras semanas de atividades, o professor revisou em aulas regulares conceitos chave para o desenvolvimento dos problemas (Leis de Newton, Leis de Conservação na Mecânica Clássica, Leis básicas da Termodinâmica e Eletromagnetismo). Durante o período, os estudantes pesquisaram em grupo as referências envolvidas no problema específico.

Após esse momento inicial, as equipes apresentaram um primeiro seminário, onde exigiu-se deles um resumo da literatura pesquisada, os conceitos físicos relevantes para a solução do problema, hipóteses levantadas pela equipe e proposta de aparato experimental para coleta dos dados.

\subsection{Fase 2 - Desenvolvimento}

Nesta fase, de aproximadamente dois meses, as equipes se reuniam durante o horário das aulas, com o professor 
e monitores voluntários nos laboratórios didáticos para discussão e implementação dos aparatos experimentais.

\subsection{Fase 3 - Apresentação final}

No final do semestre, as equipes apresentaram um seminário final, com uma revisão do primeiro seminário, discussão do aparato experimental desenvolvido, coleta de dados e análise dos resultados. Também nessa fase, cada equipe teve que escrever um esboço de artigo sobre o trabalho realizado.

\section{Análise da proposta didática}

Definir critérios para quantificar o aprendizado do estudante é um processo complexo. Uma prova onde se apresentam questões fechadas geralmente já discutidas pelo professor em sala de aula mede, muitas vezes, a capacidade de memorização do aprendiz, se distanciando de um indicativo de uma aprendizagem que seja eficiente para o estudante e que de fato possibilite o desenvolvimento da capacidade argumentativa e do entendimento sobre o que é fazer ciência.

Sem dúvida, uma mudança de abordagem metodológica, ao se aproximar das reais dificuldades do estudante, e que busque um processo educacional mais humanizado, pede um novo entendimento do processo de avaliação. Sendo assim, na disciplina aqui apresentada, nos guiamos pelo entendimento de Sant'Anna [28] sobre o processo de avaliação, ao considerar que ela é um processo no qual se busca "identificar, aferir, investigar e analisar as modificações do comportamento e rendimento do aluno, do educador, do sistema, confirmando se a construção do conhecimento se processou, seja este teórico (mental) ou prático".

Na disciplina optou-se por não aplicar provas quantitativas e buscou-se analisar a evolução individual de cada estudante ao longo do semestre. A cada apresentação das equipes, nas fases 1 e 3 detalhadas na seção anterior, cada estudante recebeu uma nota individual. Além disso, a participação nas reuniões da fase 2 também foi pontuada individualmente, de tal forma que ao final do processo a nota final de cada estudante levou em consi-deração cada um desses momentos.

A argumentação científica foi estimulada em cada uma das etapas desenvolvidas, embora muitas vezes os professores relataram terem sentido dificuldade em analisar o desenvolvimento dessa argumentação. Na subseção IV.E são apresentadas algumas considerações finais sobre esse processo de avaliação. Em consonância com a avaliação feita dos estudantes, neste relato de experiência optamos por apresentar as principais observações da equipe de professores e monitores sobre o projeto desenvolvido e a evolução contínua do aprendizado dos alunos. Os professores participantes da pesquisa (autores do artigo) ministraram o curso e se reuniram semanalmente durante todo o processo para discutir os principais aspectos observados. Foram também coletados áudios das apresentações dos grupos de estudantes, que serviram de apoio para a discussão desses pontos. Um aluno PIBIC participou de todas as etapas do processo. $\mathrm{Na}$ análise, para identificar os estudantes vamos indexar cada equipe com uma letra aleatoriamente.

\subsection{O engajamento}

Sem dúvida um dos grandes desafios do professor atualmente é envolver os estudantes em uma proposta didática que os motive a estudar e construir o próprio conhecimento. Aulas tradicionais centradas na figura do professor hoje não tem mais o apelo que tinham a décadas atrás. $\mathrm{O}$ acesso à informação disponibilizado nas redes sociais e na internet em geral, transformaram o estudante e exigiram do docente uma nova prática pedagógica, bem como a reflexão sobre a própria prática.

Nesse contexto, um primeiro ponto a ser observado foi o engajamento da turma na proposta. Acreditamos que esse comportamento esteja relacionado com um acordo "velado"selado em uma palestra com os estudantes sobre a metodologia, que ocorreu na semana de recepção à nova turma. O fato deles terem acabado de entrar na universidade e estarem sedentos por novos desafios somouse à proposta apresentada. Desde o primeiro momento pôde-se observar um enorme engajamento de grande maioria da turma nas atividades.

Como exemplo desse engajamento, citamos a situação ocorrida na equipe A. No primeiro dia de atividades, os alunos foram avisados que o problema atribuído à sua equipe poderia ser alterado, pois o professor ainda estava em dúvida sobre a viabilidade do aparato experimental. Assim, solicitou-se a eles que esperassem mais dois dias para começarem os estudos, até que o professor confirmasse se o tema se manteria ou seria trocado. No prazo estipulado, no caso um sábado à noite, um email contendo a lista final de temas foi enviado para toda a turma, sendo o tema da equipe A alterado. Imediamente os estudantes responderam a mensagem dizendo que já haviam começado a pesquisa, e que gostariam de conti-nuar com o tema inicial.

Além disso, durante todo o semestre, outros professores da faculdade, não ligados diretamente à disciplina aqui apresentada, começaram a ser procurados pelos alunos em busca de auxílio na resolução dos problemas em aberto, e a partir disso os mesmos professores pontuaram junto à coordenação do curso a mudança de postura dos estudantes da turma 2017, relatando terem percebido um maior envolvimento e uma postura mais ativa deles na busca da solução do problema proposto, mudança essa percebida em outras disciplinas e também na busca um pouco maior que o normal por iniciação científica sem bolsa de estudo na área experimental da Faculdade.

Tais relatos são alguns dos vários momentos onde pôdese observar o engajamento dos alunos no estudo, que muito além de situações puntuais como as relatadas acima, pôde ser observado pelos autores desse trabalho continuamente nas suas interações com os alunos durante 
as aulas e fora delas, como por exemplo, o aumento significativo de discussões sobre os problemas propostos nas redes sociais do grupo da sala e dos professores da faculdade.

\subsection{O desenvolvimento da autoeficácia}

A comunidade científica mundial é consideravelmente homogêna. Pesquisas indicam que a classe trabalhadora em geral e grupos sociais específicos como mulheres estão sub-representadas no mundo todo em muitos campos STEAM 29].

Como consequência "esta situação amplia as restrições que limitam a participação desses coletivos como futuros cidadãos e, paralelamente, reduz a qualidade dos produtos de inovação e desenvolvimento" 29]. Questões sociais influenciam esse comportamento, de tal forma que em regiões sem tradição de pesquisa e com baixa qualidade de ensino, como a de aplicação dessa proposta, esse comportamento é acentuado.

Um conceito diretamente ligado a esse comportamento é o de autoeficácia, entendido como sendo a auto-percepção da própria capacidade de concluir um objetivo específico ligado a algum problema STEAM. Segundo [29], a crença na autoeficácia dos estudantes em geral é mais baixa do que sua real capacidade.

No desenvolvimento do projeto, foi nítida uma mudança de percepção nesse sentido. Como exemplo, apresentamos o desenvolvimento da equipe B. Durante a primeira fase do curso, os integrantes tiveram muita dificuldade para iniciar as atividades. Procuraram o professor e os monitores várias vezes, buscando com eles a solução para o problema apresentado. No decorrer do semestre entretanto, mais acentuadamente no final da segunda fase, eles começaram a sentir-se mais confiantes na própria capacidade de encontrar as respostas às questões propostas, de tal forma que na apresentação final mostraram muita segurança e confiança no trabalho desenvolvido.

\subsection{O respeito à liberdade criativa e de estudo}

Outro ponto que vale a pena ser destacado na experiência aqui relatada foi o respeito à liberdade criativa e ao ritmo de aprendizado que uma proposta envolvendo atividades investigativas proporciona ao estudante. Esse aspecto da metodologia pode ser facilmente constatado ao se observar o rendimento da equipe C. Os estudantes da equipe se dividiram em dois um grupos, tendo um ficado responsável pela montagem do aparato experimental e outro pela modelagem teórica do experimento. O segundo grupo buscou inicialmente uma explicação física para o fenômeno usando as leis de Newton. Como o sistema era vinculado, a escolha da abordagem newtoniana para o estudo das equações de movimento mostrou-se muito complexa. Assim, por conta própria os estudantes da equipe decidiram estudar o formalismo lagrangeano em busca de ferramentas teóricas para a interpretação do fenômeno. O resultado foi surpreendente e ao final do semestre dois dos membros da equipe mostraram um domínio do formalismo condizente com alunos do ciclo avançado do curso de Física. Um artigo sobre o relato dessa experiência atualmente está em fase de finalização para submissão.

É claro que não se espera que a turma toda consiga o mesmo domínio do formalismo lagrangeano nessa fase de seu curso de graduação, mas a liberdade dada ao estudante de buscar, dentro de sua capacidade e de suas limitações, respostas ao problema proposto, aproxima essa metodologia do ritmo de estudo de cada estudante.

\subsection{Sensibilidade da metodologia à turma}

Até esse ponto apresentamos somente aspectos positivos da metodologia. Em se tratando das dificuldades, talvez a maior de todas esteja relacionada com a sensibilidade da metodologia à turma. Isso pôde ser abservado em duas situações. Na primeira delas, a mesma abordagem foi aplicada em uma disciplina de laboratório de terceiro semestre, desenvolvida também durante o primeiro semestre de 2017. Pôde-se observar que os estudantes, já acostumados com um ano de disciplinas que se utilizam de abordagens didáticas tradicionais, centradas na figura do professor, resistiram muito mais à introdução da nova proposta. Questionamentos quanto à forma de avaliar os trabalhos, à necessidade de buscar respostas ao invés de recebê-las do professor passivamente entre outras, geraram um certo desconforto nos estudantes e dificultaram o andamento do curso. Comportamento similar pôde ser observado em outra turma de ingressantes no curso de Física, que se iniciou no segundo semestre de 2017.

Em ambas as situações houve necessidade de adaptações na proposta original que respeitassem o ritmo dos alunos. No curso de laboratório as mudanças foram menores e implicaram apenas em um novo planejamento das apresentações das atividades, permitindo aos estudantes mais tempo na preparação dos experimentos. Já para a turma de ingressantes de segundo semestre, em muitos dos horários de reunião com as equipes e desenvolvimento dos aparatos experimentais, os estudantes não apareciam e foi necessário intercalar aulas de conteúdos específicos para toda a turma com as reuniões com as equipes de forma a manter o estímulo à presença dos estudantes nas atividades propostas.

Assim, podemos perceber que o docente que se propõe a uma mudança de paradigma, dividindo a responsabilidade do processo do ensino-aprendizagem com o estudante, e tornando-se agora um mediador desse processo, ao invés de agente principal, deve ter consciência que muitas vezes um programa preestabelecido no início do semestre precisará de ajustes. Isso é esperado de uma metodologia que não trata mais o estudante como um mero receptor de informações. 


\subsection{Outros aspectos relevantes}

Entre outras dificuldades encontradas, podemos citar que a escolha do problema e a dificuldade envolvida na construção do aparato experimental influenciam diretamente no desenvolvimento da argumentação científica. Estruturas lógicas de causa e efeito que podem ser testada em um aparato experimental bem posto, são difíceis de serem observadas em experimentos de construção mais elaborada. Nesse momento, a existência de um apoio logístico de técnicos de laboratório facilita muito o desenvolvimento da metodologia.

Outra dificuldade encontrada foi na busca de indicadores para o desenvolvimento da argumentação científica por parte dos estudantes, de sua evolução no domínio dos conceitos físicos relevantes, e na própria evolução de cada estudante. Geralmente os professores de Ciências Naturais e Exatas estão acostumados com provas quantitativas e sentem desconforto em avaliar os estudantes qualitativamente. Os pesquisadores participantes da pesquisa relataram ter sentido dificuldade no processo de avaliação qualitativo que ocorreu de maneira contínua ao longo do semestre, muitas vezes não conseguindo pontuar objetivamente a evolução de cada aluno. Sendo assim, entendem que é necessário mais estudos de forma a, por exemplo, serem capazes de utilizar com propriedade os critérios de Sant'anna na avaliação dos estudantes e da proposta em si, e pretendem no futuro fazer um estudo mais detalhado da avaliação desta proposta didática de forma a contribuir para diminuir esse sentimento.

Também observou-se que os estudantes preferem escolher os temas. Assim, uma mudança que será implementada em futuras aplicações da metodologia é na escolha dos temas.

\section{Considerações Finais}

Muito embora a análise dos resultados tenha sido de cunho qualitativo, e somente apresentando as principais observações dos docentes que desenvolveram a proposta, acreditamos que o relato seja válido, na medida em que uma mudança de prática pedagógica desse porte requer do professor muita reflexão e disposição para lidar com as angústias e questionamentos que qualquer mudança de paradigma implica. Assim, ao relatar os principais pontos observados, esperamos poder contribuir para que outros docentes de cursos de graduação sintam-se mais propensos a utilizar atividades investigativas em sua prática pedagógica e que possam lidar com as dificuldades encontradas com maior conhecimento do assunto.

\section{Referências}

[1] J. Praia, J.D. Gil-Pérez e A. Vilches, Cien. Educ. 13, 141 (2007).

[2] D. Allchin, Scien. Educ. 23, 1911 (2014).
[3] http://g1.globo.com/jornal-nacional/noticia/ 2017/08/cientistas-dos-eua-confirmamaquecimento-global-que-trump-nega.html, acessado em 10/01/2018.

[4] C.Z. de Oliveira, E.F.V. de Andrade, D.P. dos Santos Nogueira, E. de Azevedo Cantão, K.M. de Melo da Rocha, F.S.R. Nunes e S. Perez, in $5^{\circ}$ Congresso ibero-americano em investigação qualitativa (CIAIQ, Porto, 2016).

[5] B.V. Street, Jour. Res. Read. 16, 81 (1993).

[6] M. Fayol e M. Bagno, Numeramento: aquisição das competências matemáticas (Parábola Editorial, São Paulo, 2012).

[7] L.H. Sasseron, in Ensino de Ciências por investigação editado por A.M.P. Carvalho (Cengage Learning, São Paulo, 2013).

[8] http://inep.gov.br/cenario-educacional, acessado em 20/04/2018.

[9] http://pne.mec.gov.br/images/pdf/pneconhecendo-20-metas.pdf acessado em 20/01/2018.

[10] L.N. Magacho e A.F. Nascimento Junior, Revista da SBEnBio 7, 4598 (2014).

[11] B.A. Gatti e M.M.R. Nunes, Formação de Professores para o ensino Fundamental: estudo de currículos das Licenciaturas em Pedagogia, Língua Portuguesa, Matemática e Ciências Biológicas. Coleção Textos FCC, Fundação Carlos Chagas (FCC/DPE, São Paulo, 2009).

[12] M.A. Moreira, Textos de Apoio ao Professor de Física 26, 6 (2015).

[13] A.L. Manrique, Educ. Matem. Pesq. 11, 515 (2009).

[14] A.F. Zompero, C.E.S. Gonçalves e C.E. Laburú, Cien. Educ. 23, 419 (2017).

[15] F.N. Castro, N.C. Maia, C.S. Nascimento e S. Perez, Rev. Bras. Ens. Fis. 40, e1503 (2018).

[16] M.A. Braga, Diálogo entre as múltiplas perspectivas na pesquisa em ensino de Física editado por L.G.R. Genovese (Livraria da Física, SP, 2016).

[17] http://www.project2061.org/publications/sfaa/ online/sfaatoc.htm acessado em 20/01/2018.

[18] A.F. Zômpero e C.E. Laburú, Ens. Pesqui. Educ. Ciênc 13, 67 (2011).

[19] I.M. Greca, J.A.M. Villagrá e M.D. Ojeda, Rev. Elect. Ens. Cienc. 16, 231 (2017).

[20] T.I. Pasqualetto, E.A. Veit e I.S. Araújo, Rev. Bras. Pesq. Ens. Cienc. 17, 551 (2017).

[21] C.V. Schwarz e Y.N. Gwekwerere, Scien. Educ. 91, 158 (2007).

[22] R.B. Toma, I.M. Grega e J.A.M. Villagrá, Rev. Eureka Ens. Divulg. Cienc. 14, 442 (2017).

[23] http://www.iypt.com.br acessado em 20/01/2018.

[24] P. Hewitt, Física Conceitual (Bookman, Porto Alegre, 2002).

[25] O. Freire Jr. O universo dos quanta: uma breve história da Física Moderna (FTD, São Paulo, 1997).

[26] J. Walker, O circo voador da Física (LTC, São Paulo, 2008).

[27] N.C. Maia, A dança dos surdos. Trabalho de conclusão de curso, Universidade Federal do Pará, Pará (2017).

[28] I.M. Sant'anna, Por que Avaliar? Como avaliar? Critérios e instrumentos (Vozes, Rio de Janeiro, 2001).

[29] http://crecim.uab.cat, acessado em 20/01/2018. 